\title{
Monitoring liver disorders in vinyl chloride monomer workers using greyscale ultrasonography
}

\author{
D. M. J. WILLIAMS ${ }^{1}$, P. M. SMITH ${ }^{2}$, K. J. W. TAYLOR ${ }^{3 *}$, \\ I. R. CROSSLEY ${ }^{2}$, and B. W. DUCK ${ }^{4}$
}

BP Chemicals International Ltd, Sully, Penarth, South Glamorgan CF6 2YU1 ; Department of Medicine, Welsh National School of Medicine, Llandough Hospital, Penarth ${ }^{2}$; Department of Nuclear Medicine-Ultrasound, Royal Marsden Hospital, Sutton ${ }^{3}$; and Occupational Health Unit, BP Research Centre, Sunbury-on-Thames ${ }^{4}$

\begin{abstract}
Williams, D. M. J., Smith, P. M., Taylor, K. J. W., Crossley, I. R., and Duck, B. W. (1976). British Journal of Industrial Medicine, 33, 152-157. Monitoring liver disorders in vinyl chloride monomer workers using greyscale ultrasonography. Recognition that vinyl chloride could be hepatotoxic led to a survey of workers to determine whether changes had been induced by past exposure, and to evaluate standard liver function tests as monitors of early liver abnormalities. Standard liver function tests were found to be unsuitable for the detection of such abnormalities in the population at risk. Of 487 workers examined, $102(20.9 \%)$ had abnormalities on initial testing but only two were finally shown to have portal hypertension; in both cases, thrombocytopaenia provided the first diagnostic evidence since liver function tests were normal. Furthermore, $40(35.7 \%)$ of 112 control subjects had initial test abnormalities. A sample of 19 workers with various exposures to vinyl chloride monomer were examined blind by greyscale ultrasonography. Five with minimal or no exposure were confirmed as normal but 12 of the remainder had abnormalities. These consisted of an enlarged portal vein (seven instances), splenomegaly (eight), and changes in hepatic texture (seven). Five of these 12 cases had previously been considered normal. It was concluded that greyscale ultrasonography had many advantages over standard methods for screening workers exposed to hepatotoxic chemicals, and should be the subject of a large scale evaluation.
\end{abstract}

In 1974 it was reported that angiosarcoma of the liver had been recognized in workers exposed to vinyl chloride monomer (Creech and Johnson, 1974; Block, 1974). Although only two such cases have been reported in the United Kingdom (Lee and Harry, 1974; Smith, Williams, and Evans, 1976) the possibility was raised that angiosarcoma might not be the only change to be found in association with exposure to vinyl chloride monomer, and that periportal fibrosis, causing portal hypertension, oesophageal varices, and splenomegaly might be more common manifestations of toxicity (Marsteller

*Present address: Department of Radiology, Yale University School of Medicine, Connecticut. et al., 1973; Smith and Williams, 1974; Makk et al., 1974; Lange et al., 1974; Thomas et al., 1975).

In the course of the survey of exposed workers that was initiated throughout the industry after reports from the United States of America of angiosarcoma, 487 workers were examined in a large factory which produced more than 100000 tonnes of polyvinyl chloride annually (Williams et al., 1975). Two of the workers were found to have portal hypertension due to periportal fibrosis, with oesophageal varices and splenomegaly. Both cases had been initially identified by thrombocytopaenia of $72000 \mathrm{~mm}^{3}$ and $45000 \mathrm{~mm}^{3}$ respectively, and the suspected diagnosis was confirmed by barium 
swallow, radiography of the abdomen for spleen size, splenic venography, and needle liver biopsy. Standard liver function tests had shown only minimal and non-diagnostic changes with a marginally raised bilirubin in one patient $(18 \mu \mathrm{mol} / \mathrm{l})$ and slightly elevated $\gamma$-glutamyl transpeptidase levels (66 IU/1 and $82 \mathrm{IU} / 1$; normal range less than $45 \mathrm{IU} / 1)$. Since in both these patients changes were advanced we were forced to consider whether the current methods of screening by full blood counts and liver function tests could be relied upon to detect the subtle changes described, since even needle liver biopsy may be normal in cases where a wedge biopsy has revealed an inconspicuous periportal fibrosis (Smith and Williams, 1974).

Greyscale ultrasonography was suggested as being an attractive alternative method of detecting such changes as it is a non-invasive technique applicable to mass-screening programmes (Taylor et al., 1975); and a blind trial was devised to test this suggestion.

\section{Patients and methods}

Nineteen volunteers who had already been screened were chosen from the factory; they covered a wide range of ages and exposures to vinyl chloride monomer (Table 1). Two were administrative staff known to have had only very low exposures (less than $0.05 \mathrm{ppm}$, Cases 1,2 ), one had had mainly intermittent low level exposure (up to 25 ppm, Case 3) while the remainder had had exposures of up to $200 \mathrm{ppm}$ or more (Cases 4-19), including periods as polycleaners (Cases 4, 5, 7, 9, 10, and 11).

On routine screening Cases 1-3 and 5-8 were apparently normal; the remainder exhibited various abnormalities and as a result of further investigations Cases 17 and 18 were shown to have portal hypertension. Case 19 was included as he had had a portacaval shunt in 1968 for bleeding oesophageal varices; since then he had not been exposed to vinyl chloride.

Routine screening comprised clinical examination for stigmata of liver disease, urine analysis, platelet counts, and standard liver function tests (serum proteins, bilirubin, alkaline phosphatase, SGOT, SGPT and $\gamma$-glutamyl transpeptidase). A repeated abnormality in one or more of these variables then led to further investigations which included bromsulphthalein retention, barium swallow, radiography of the abdomen for spleen size, fibre oeso-, phagoscopy, splenic venography, and liver biopsy. In addition tests for smooth-muscle and mitochondrial antibodies and Australia antigen were performed where indicated; all were negative or only weakly positive. The only abnormal haematological findings were low platelet counts in Cases 17, 18, and 19. Radiography showed splenomegaly and oesophageal varices in Cases 17,18 , and 19.

The 19 volunteers were then examined by the ultrasound operator (KJWT) who had no knowledge of clinical and laboratory findings, nor of their industrial exposure.

The ultrasound examination consisted of moving a hand-held focusing transducer across the skin which had been smeared lightly with mineral oil as a coupling agent. The liver was scanned in a series of parasagittal sections by moving the transducer through an arc (Fig. 1). The portal vein was displayed in a suitable parasagittal plane. The spleen could be scanned along the left tenth intercostal space with the patient lying in the right lateral position, and a measure of spleen size obtained from the longitudinal axis. Figs 2 and 3 show the contrasting appearance of the liver consistency,

TABLE 1

Duration and LeVels (PPM) of ExPosures to Vinyl Chloride Monomer

\begin{tabular}{|c|c|c|c|c|c|c|c|}
\hline \multirow[b]{2}{*}{ Case } & \multirow[b]{2}{*}{$\begin{array}{c}\text { Age } \\
\text { (years) }\end{array}$} & \multicolumn{3}{|c|}{ Constant exposure (months) } & \multicolumn{3}{|c|}{ Intermittent exposure (months) } \\
\hline & & $\begin{array}{l}\text { Low } \\
0-25\end{array}$ & $\begin{array}{c}\text { Medium } \\
25-200\end{array}$ & $\begin{array}{c}\text { High } \\
200+\end{array}$ & $\begin{array}{l}\text { Low } \\
0-25\end{array}$ & $\begin{array}{c}\text { Medium } \\
25-200\end{array}$ & $\begin{array}{c}\text { High } \\
200+\end{array}$ \\
\hline $\begin{array}{r}1 \\
2 \\
3 \\
4 \\
5 \\
6 \\
7 \\
8 \\
9 \\
10 \\
11 \\
12 \\
13 \\
14 \\
15 \\
16 \\
17 \\
18 \\
19\end{array}$ & $\begin{array}{l}\left.\begin{array}{l}41 \\
40\end{array}\right\} \\
32 \\
45 \\
48 \\
45 \\
36 \\
47 \\
30 \\
45 \\
56 \\
39 \\
41 \\
42 \\
50 \\
55 \\
32 \\
43 \\
46\end{array}$ & Very low & $\begin{array}{r}78 \\
\\
69 \\
186 \\
\\
46 \\
80 \\
32 \\
153 \\
78 \\
88 \\
84\end{array}$ & $\begin{array}{l}15 \\
10 \\
27 \\
27 \\
30 \\
20\end{array}$ & $\begin{array}{r}76 \\
127 \\
40 \\
100 \\
89 \\
\\
8 \\
1 \\
\\
39 \\
38 \\
215 \\
\\
38 \\
42 \\
77\end{array}$ & $\begin{array}{r}17 \\
184 \\
43 \\
22 \\
78 \\
\\
63\end{array}$ & $\begin{array}{l}10 \\
28\end{array}$ \\
\hline
\end{tabular}




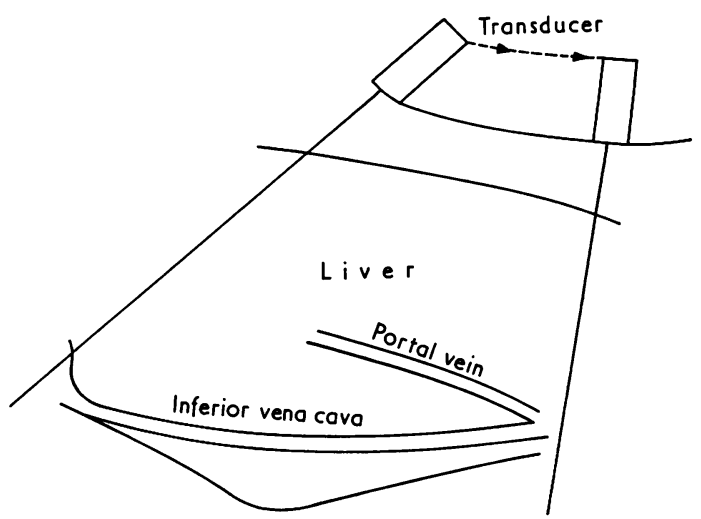

FIG. 1. Diagram showing movement of transducer to display anatomical features shown in Fig. 2. Portal vein is shown anterior to the inferior vena cava.

portal vein size and configuration in a normal patient and one with portal hypertension in whom the portal vein is enlarged and tortuous. Although there is evidence of fatty infiltration and fibrosis, the non-cirrhotic fibrosis of vinyl chloride-related portal hypertension is much less obvious than in cirrhotics with an equivalent degree of portal hypertension. When the spleen was secondarily enlarged, it had a characteristic pattern which could be distinguished from malignant or chronic inflammatory causes of splenomegaly (Taylor and Milan, 1976).

The equipment was a custom-built Marsden machine with a transducer diameter of $18 \mathrm{~mm}$ and a frequency of 3.0 $\mathrm{MHz}$ with a variable swept-gain rate. Machines of similar potential are now becoming available commercially. Most ultrasound machines were originally designed for obstetric use, such as revealing the uterine contents, and hence merely display the contours of organs. It is the greyscale capacity of the machine used in this assessment that enabled the internal consistency of the liver and spleen to be displayed. There is no evidence of hazard with this procedure at diagnostic levels (Taylor and Dyson, 1972), unlike the dose accumulation problem which limits routine radiography; nor is there an unacceptable incidence of equivocal scans as is associated with radioisotope examination (Conn and Elkington, 1968) which also gives a small but significant ionizing radiation exposure.

Repeatability can be achieved by standardizing the setting of the machine and by using the gallbladder as an anatomical landmark for successive cuts.

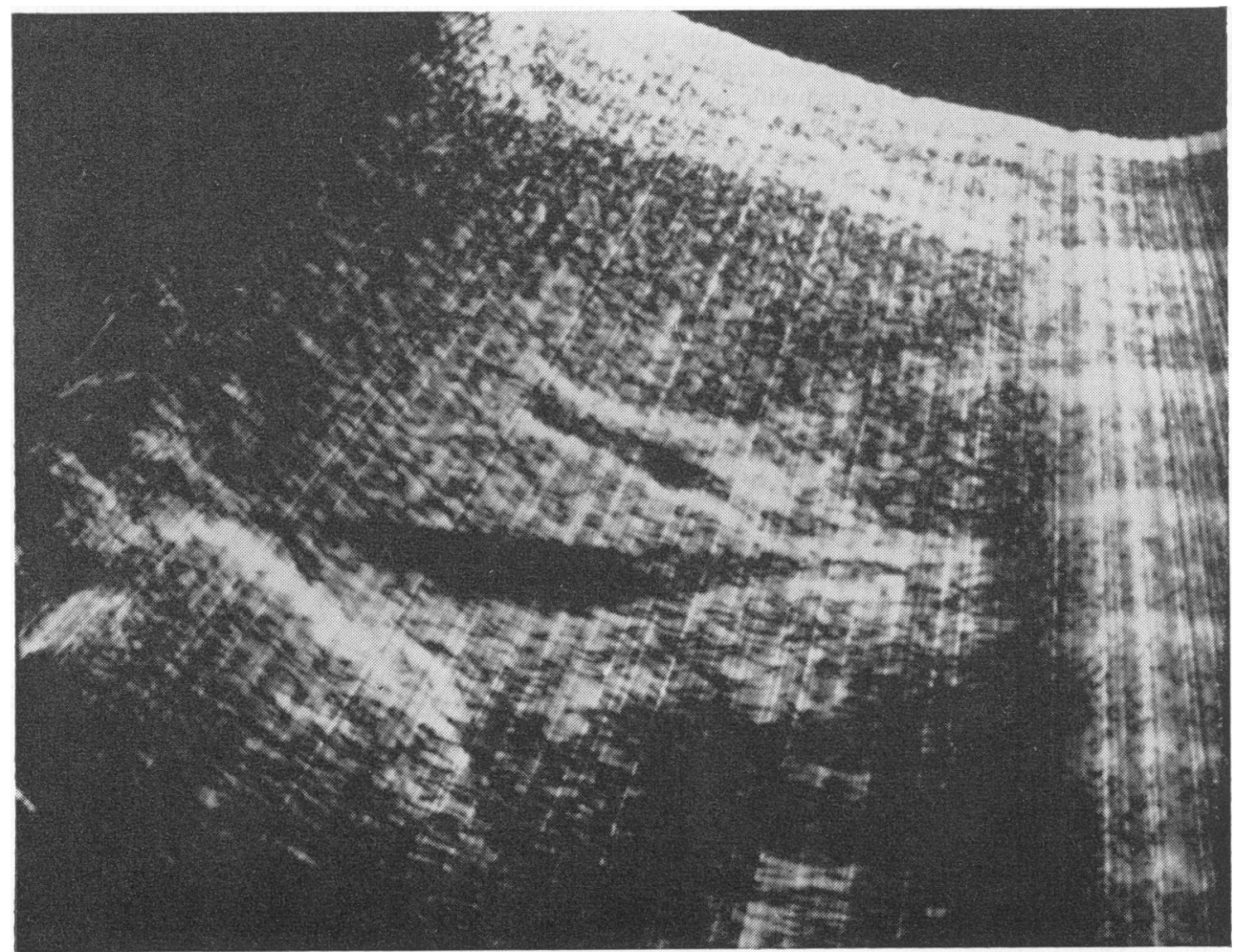

FIG. 2. Parasagittal scan of liver $2 \mathrm{~cm}$ to right of midline showing normal liver consistency, the portal vein, and inferior vena cava. 


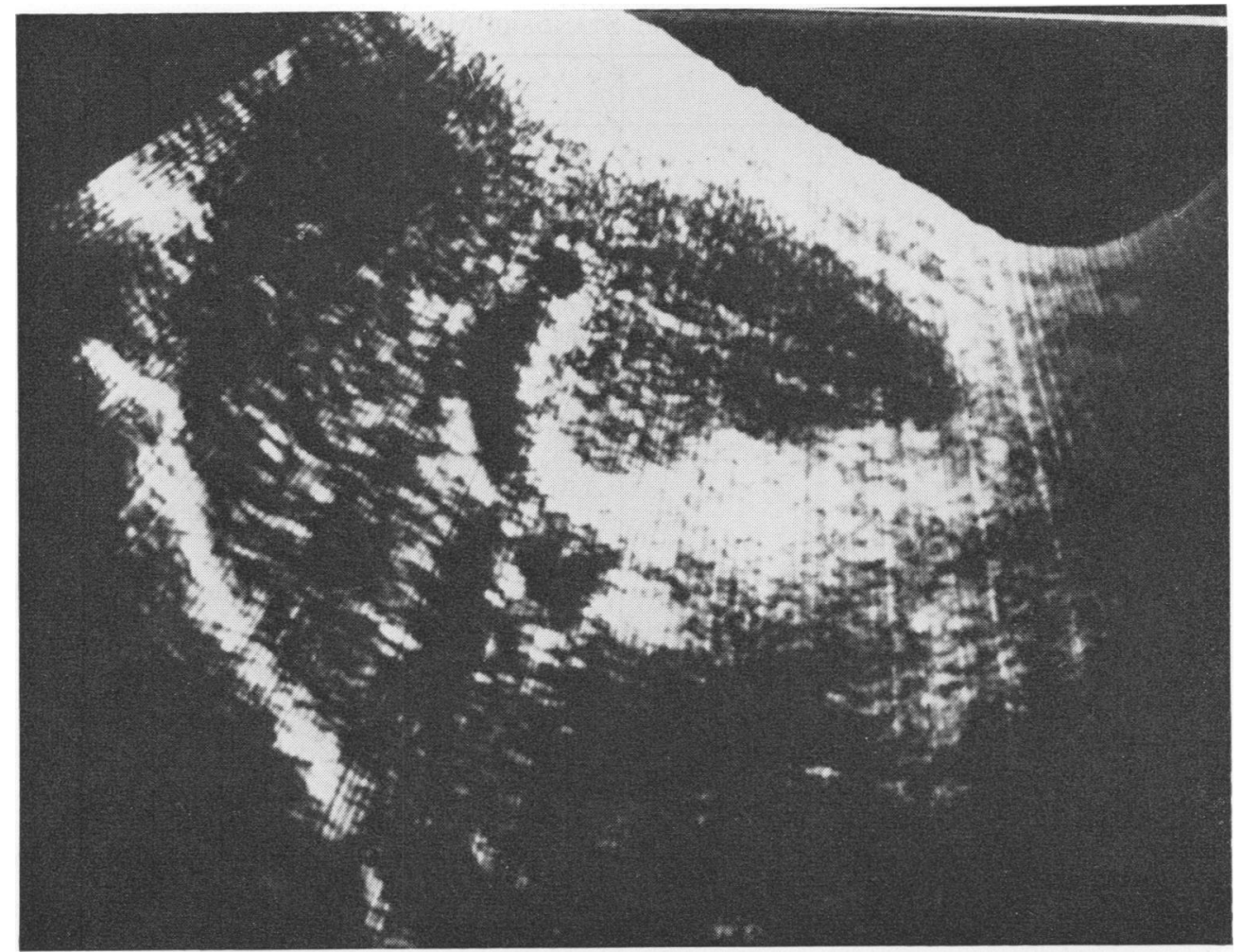

FIG. 3. Parasagittal section of liver from patient with vinyl chloride-related portal hypertension.

Portal vein is dilated and highly tortuous.

\section{Results}

The abnormalities found by the two methods are compared in Table 2. Cases that were known to exhibit liver dysfunction $(4,9,11,15,17-19)$ were confirmed by ultrasonography. Normality was confirmed in Cases 1, 2, 3, 5, and 12 and the biopsy and biochemical changes in Cases 13 and 16, clinically of dubious significance, were not substantiated. It is the additional information given in Cases 6, 7, 8, 10 , and 14 that emphasizes the advantages of ultrasound. In these five patients, in whom there had been no previous evidence of abnormality, ultrasonography showed changed liver texture, splenic vein enlargement, or increased spleen size.

\section{Discussion}

It is not suggested that ultrasound is necessarily superior to other techniques if these are carried out with meticulous care, but there are considerable savings in time for medical staff, and in exposure of patients to investigation, all of major importance when large numbers of workers are to be investigated. In this factory alone some 450 men qualify for medical supervision under the Vinyl Chloride Code of Practice for Health Precautions (1975) with another 300 or more exposed intermittently, or in fringe areas where supervision is not at present required. A further 50 men have been exposed previously and are still working on the site.

Although this preliminary work appears impressive to us, the number of subjects is small and perhaps discovery of unequivocal cases of portal hypertension not revealed by standard tests has led to overvaluation of the method. On full scale evaluation, it may be that difficulties in standardizing and interpreting results, particularly in borderline cases, will reduce its attractiveness. There are problems in carrying out a full survey, since in this factory about 450 polymerization workers have had a substantial exposure to vinyl chloride monomer for more than a year. Until a mobile unit is available, men must go to the machine but in such a way that neither their work nor free time is disrupted. Evaluation will depend upon the co-operation of a medical physicist, a radiologist familiar with ultrasound, and a clinician with a special interest in liver disease based at a major hospital. Fortunately all these are available 
TABLE 2

Comparison of Abnormalities Detected by Standard Methods and by Ultrasonography

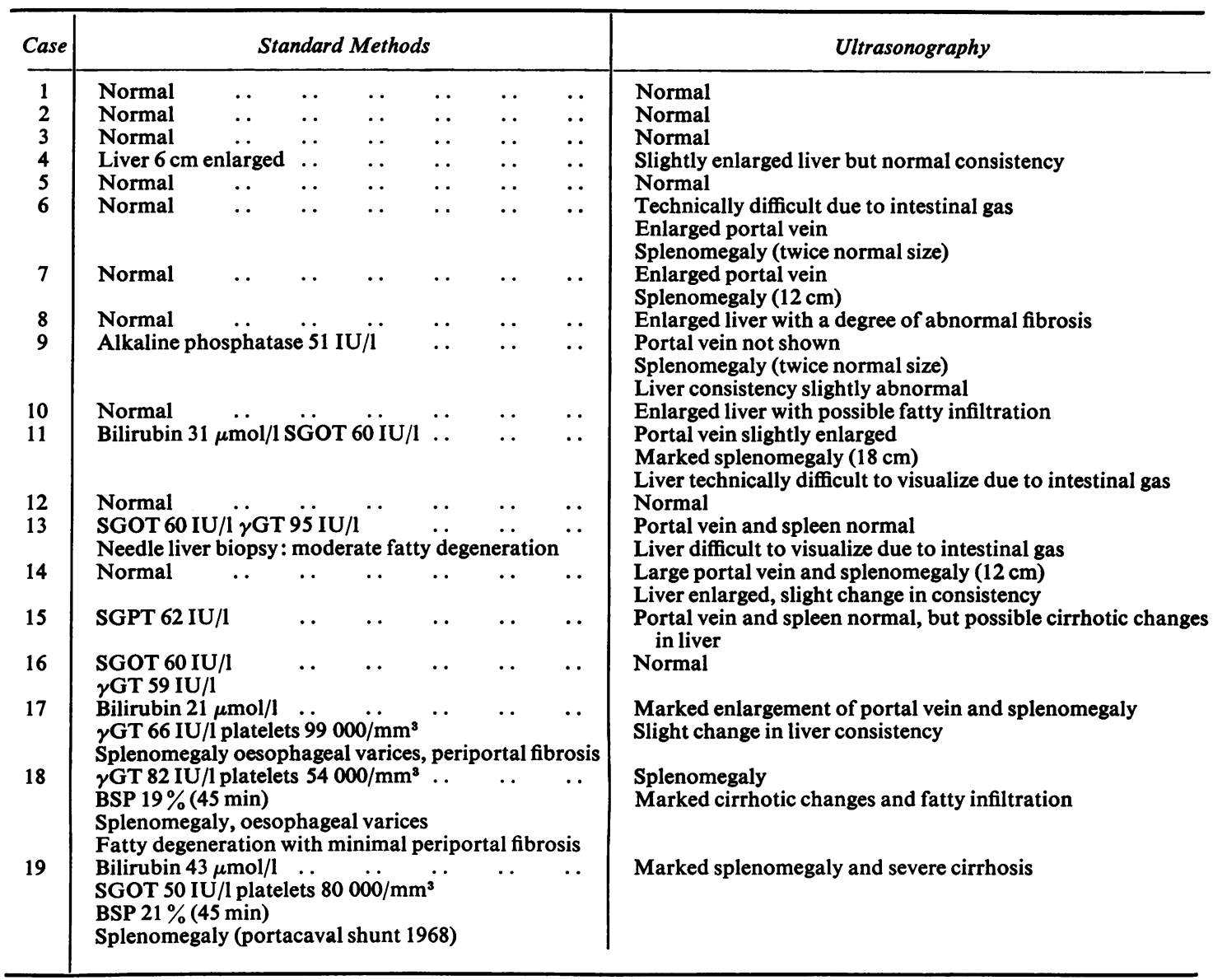

to us locally. Commercial machines are being refined in the light of experience and modifications can be made in them if required, particularly during the development of the grey scaling which is necessary for assessment of liver texture. The manufacturers (Nuclear Enterprises Ltd, Edinburgh) can now promise a resolution of $2 \mathrm{~mm}$ which should be sufficient for this.

In the population from which these volunteers were chosen, 487 men were examined using traditional methods. On initial testing $102(20.9 \%)$ had abnormal biochemical or haematological results. Further testing yielded a group of 20 men with persistently abnormal findings, which led to intensive investigation including hospital admission. If such tests were continued, a large number of false-positives which lengthened the screening time for some men might result in a loss of morale and of faith in their value.

\section{Conclusion}

The advantages of greyscale ultrasonography over more traditional methods of liver investigation appear to be considerable: they include better patient acceptability, savings in time and effort, and earlier and more definite indications of pathological changes in structure.

Hence it is considered that further studies should be carried out on a larger scale to evaluate the suitability of this technique for the screening of chemical workers exposed to vinyl chloride and other potentially hepatotoxic agents. A mass study could evaluate translation of the grey scaling into a numerical value by computer. It could also determine whether there will be any progressive deterioration, now that vinyl chloride monomer exposure levels have been reduced so much, in those patients already shown to have changes in liver texture due to non-cirrhotic periportal fibrosis. 
We wish to acknowledge the specialist help given by the Staff of BPCI, Barry, and the co-operation of the volunteers from the factory. We also thank Dr V. R. McCready for the facilities of his department at the Royal Marsden Hospital. Professor P. J. Scheuer kindly gave additional help with the histology.

\section{References}

Block, J. B. (1974). Angiosarcoma of the liver following vinyl chloride exposure. Journal of the American Medical Association, 229, 53-54.

Conn, H. O. and Elkington, S. G. (1968). Is hepatic scanning overrated? Gastroenterology, 54, 135.

Creech, J. L. and Johnson, M. N. (1974). Angiosarcoma of liver in the manufacture of polyvinyl chloride. Journal of Occupational Medicine, 16, 150-151.

Lange, C. E., Jühe, S., Stein, G., and Veltman, G. (1974). Die sogenannte Vinylchlorid-Krankheiteine berufsbedingte Systemsklerose? Internationale Archiv für Arbeitsmedizin, 32, 1-32.

Lee, F. I. and Harry, D. S. (1974). Angiosarcoma of the liver in a vinyl chloride worker. Lancet, 1, 1316-1318.

Makk, L., Creech, J. L., Whelan, J. G., and Johnson, M. N. (1974). Liver damage and angiosarcoma in vinyl chloride workers. Journal of the American Medical Association, 230, 64-68.

Marsteller, H. J., Lelbach, W. K., Muller, R., Jühe, S., Lange, C. E., Rohner, H. G., and Veltman, G. (1973). Chronisch-toxische Leberschaden bei Arbeitern in der
PVC-Produktion. Deutsche Medizinische Wochenschrift, 98, 2311-2314.

Smith, P. M. and Williams, D. M. J. (1974). Vinyl chloride and cirrhosis. Digestion, 10, 321-322.

,-- , and Evans, D. M. D. (1976). Angiosarcoma in a vinyl chloride worker. Bulletin of the New York Academy of Medicine, 52, 447-452.

Taylor K. J. W. and Dyson, M. (1972). Possible hazards of diagnostic ultra-sound. British Journal of Hospital Medicine, 8, 571-577.

_ and Milan, J. (1976). Digital A-scan analysis in the diagnosis of chronic splenic enlargement. In Proceedings of the Conference on Tissue Signatures at the National Bureau of Standards, Washington, edited by M. Linzer. (In press).

—, Williams, D. M. J., Smith, P. M., and Duck, B. W. (1975). Grey-scale ultrasonography for monitoring industrial exposure to hepatotoxic agents. Lancet, 1, 1222-1224.

Thomas, L. B., Popper, H., Berk, P. D., Selikoff, I., and Falk, H. (1975). Vinyl chloride-induced liver disease from idiopathic portal hypertension (Banti's syndrome) to angiosarcomas. New England Journal of Medicine, 292, 17-22.

Vinyl Chloride Code of Practice for Health Precautions. (February 1975). Health and Safety Executive, Baynards House, 1 Chepstow Place, London W2 4TY.

Williams, D. M. J., Taylor, K. J. W., Crossley, I. R., Smith, P. M., and Duck, B. W. (1975). Pre-symptomatic detection of liver changes in vinyl chloride monomer workers. Digestion, 12, 362.

Received for publication 10 September 1975

Accepted for publication 22 December 1975 